\title{
A SUBJETIVIDADE CONTEMPORÂNEA: UMA NOVA FRONTEIRA PARA A EDUCAÇÃO AMBIENTAL
}

\section{CONTEMPORARY SUBJECTIVITY: A NEW BORDER FOR ENVIRONMENTAL EDUCATION}

\author{
Ana Lizete Farias ${ }^{1}$ \\ Maria do Rosário Knechtel ${ }^{2}$
}

\section{RESUMO}

Este trabalho tem como objetivo contribuir com discussões sobre violência e sofrimento, enquanto integrantes da subjetividade contemporânea, em comunidades tradicionais, em especial aquelas localizadas em ambientes costeiros, com ênfase no litoral do Paraná, Brasil. Diante o sofrimento psíquico em situações de injustiça ambiental, julgamos importante que a Educação Ambiental partilhe da responsabilidade na reorganização do campo simbólico desses sujeitos, no que se refere aos bens naturais. Propomos que esses elementos sejam incluídos na construção de uma Educação Ambiental, enquanto instrumento de intervenção coletiva em esferas públicas.

Palavras chave: Sofrimento, Violência, Psicanálise, Educação Ambiental, Oceanografia Socioambiental.

\section{ABSTRACT}

This paper aims to contribute to discussions about violence and suffering, as members of contemporary subjectivity, in traditional communities, especially those located in coastal environments, with emphasis on the coast of Paraná, Brazil. In the face of psychic suffering in situations of environmental injustice, we believe it is important for Environmental Education to share responsibility for the reorganization of the symbolic field of these subjects with regard to natural goods. We propose that these elements be included in the construction of an Environmental Education, as an instrument of collective intervention in public spheres.

Keywords: Suffering, Violence, Psychoanalysis, Environmental Education, Socioenvironmental Oceanography.

\footnotetext{
${ }^{1}$ Doutoranda no Programa de Meio Ambiente e Desenvolvimento da UFPR. Mestre em Geologia Ambiental pela UFPR. Bacharel em Geologia pela UFRGS. Pesquisadora do Núcleo de Direito e Psicanálise da UFPR, Integrante do Grupo de Pesquisa "Epistemologia e Sociologia Ambiental" (CNPq). Bolsista do sistema CAPES E-mail: analizete@gmail.com

${ }^{2}$ Doutora em Sociologia da Educação pela Universidade Federal de Santa Maria (UFSM), PósDoutora em Educação Permanente e a Distância pela Universidad Nacional de Educacíon a Distancia (UNED), na Espanha, e Pós-Doutora em Sociologia e Educação Ambiental pela Universidade de Berlim, Karlsruhe, na Alemanha. MSc em Ciências Sociais pela Universidade de São Paulo. Atualmente é professora e pesquisadora do Programa de Pós Graduação em Meio Ambiente e Desenvolvimento da Universidade Federal do Paraná (UFPR). Email: mknechtel10@gmail.com
} 


\section{INTRODUÇÃO}

(...) Contemporâneo não é apenas aquele que, percebendo o escuro do presente, nele apreende a resoluta luz; é aquele que dividindo e interpolando o tempo, está a altura de transformá-lo

e de colocá-lo em relação com outros tempos, de nele ler de modo inédito a história, de 'citá-la' segundo uma necessidade que não provém de seu arbítrio, mas de uma exigência à qual ele não pode responder. É como se aquela invisível luz, que é o escuro do presente, projetasse a sua luz sobre o passado, e este, tocado, por esse facho de sombra, adquirisse a capacidade de responder às trevas do agora (Giorgio

Agamben, 2009: 59).

O texto de Giorgio Agamben é uma provocação para começarmos a falar sobre a subjetividade contemporânea e sua relação com as questões socioambientais, no âmbito das regiões costeiras. O autor, que reconhecidamente através de sua obra, propõe o desafio de pensar nossa época moderna, nos interroga, enquanto sociedade, sobre os significados da ética em nosso tempo. Desta forma, "perceber o escuro" pode ser compreendido não como algo negativo, mas sim uma atividade ou habilidade particular de interpelá-lo como algo que nos concerne, algo da ordem de nossa responsabilidade. Há, ainda, uma noção de inconformidade, que entendemos que o autor propõe em relação aos contornos que a nossa época assume, que sugere uma escolha: ficar preso às impossibilidades desse tempo ou se colocar à frente dele, numa nítida ruptura com essa condição.

No tocante aos aspectos socioambientais, as palavras de Agamben se ajustam ao necessário reconhecimento de que os tempos que vivemos exigem esta postura de inconformidade, demandando medidas e transformações profundas e por que não, uma ruptura com a ordem econômica vigente? A crise climática mundial, a exploração exaurível do ambiente natural, físico-biológico, a poluição dos oceanos, os desastres ecológicos e humanos em escala sem precedentes, ou seja, o fato de estarmos erodindo as bases de nossa economia, nossos meios de sobrevivência, já deveriam ser considerados imperativos para esta ruptura. No entanto, algo nos escapa aí, pois não há consenso sobre o real estado do mundo no tocante às condições e exigências para a vida em comum no planeta, ou melhor, não há um consenso sobre a crise ambiental em que estamos imersos.

Esta via, portanto, da perspectiva de inconformidade trazida na reflexão de Agamben, interessa a nós, de forma particularizada em relação à Educação 
Ambiental, no âmbito dos desafios da Oceanografia Socioambiental. Marcamos a necessidade de rompimento com aquilo que nos parece irremediavelmente preso a determinadas convicções, alegorias e formas de vida, retomando a capacidade de estranhamento, de recusa de uma condição de vítima das formas de opressão, como as que envolvem a apropriação dos bens naturais.

O que pode, então, a psicanálise, que foi criada para investigar a razão inconsciente do sofrimento individual contribuir diante das questões socioambientais da nossa era contemporânea? Para responder a essa questão antes é preciso lembrar a proposta de Freud sobre o inconsciente, ou seja, este se caracteriza como uma instância psíquica marcada por uma particular maneira de operar, regulado por leis diferentes daquelas ordenadoras da consciência. Portanto, além de ser um sistema com lógica própria e, via de regra, adversa à da consciência, o inconsciente, para Freud, é o que genuinamente constitui a subjetividade, e não apenas um detalhe dela.

Mais tarde, Lacan dirá no seu Seminário 14, a Lógica do Fantasma, que "o inconsciente é a política", uma frase que será endereçada aos psicanalistas em outra de suas falas: "que antes renuncie a isto quem não conseguir alcançar em seu horizonte a subjetividade de sua época (Lacan,1998: 322)”.

Resta-nos, portanto, indagar o que é a subjetividade da nossa época, ou ainda, qual o modo com que apreendemos o mundo para decidir e tomar decisões?

Dunker (2011) identifica a alienação enquanto um bloqueio de experiência, situação em que o sujeito é incapaz de se reconhecer em sua própria história particular ou tem dificuldade de estabelecer formas sociais universalmente compartilháveis.

Mas é Roudinesco (2000: 2) que resume de maneira bastante expressiva ao dizer que a nossa subjetividade "é o campo da morte, das paixões, a sexualidade, da loucura, do inconsciente e a relação com o outro".

Em suma, não é mais novidade que as transformações sociais, econômicas e culturais alcançadas na contemporaneidade modificaram também as formas de constituição da nossa subjetividade e compreendê-las do ponto de vista das questões socioambientais pode contribuir com a reflexão e transformação profunda das nossas práticas sociais coletivas em termos ambientais. 
A psicanálise, nesse sentido, pode nos ajudar a compreender que não se trata apenas de olhar os acontecimentos a partir de suas expressões físicas - as catástrofes, os desastres ecológicos, a perversidade humana, etc.- mas sim como os sujeitos elaboram esses acontecimentos de forma a construir a nossa responsabilidade em tudo isso, uma opção certamente mais interessante do que a vitimização ou culpa.

Isto posto, a partir de algumas particularidades das comunidades tradicionais do litoral do Paraná, desenvolveremos uma discussão de cunho teórico, colocando em cena alguns conceitos orientados pela psicanálise, para ressaltar importância dos aspectos subjetivos em cenários de injustiça ambiental. Abordaremos o tema da violência e sofrimento e as consequências daquilo de Vladimir Safatle (2017), um dos mais importantes pensadores brasileiro, chama de melancolização do poder e a sua correlação com as questões socioambientais.

É nosso objetivo avançar um tanto a mais nesta construção de maneira a contribuir na concepção de uma Educação Ambiental crítica, tendo como base empírica a paisagem costeira, em especial a região litorânea do Paraná.

Neste sentido há que se pedir a compreensão para o fato de que não é nosso objetivo apresentar um diagnóstico extenso das condições sociais e ambientais no senso estrito, visto que há um grupo de pesquisadores que se dedicam a isto, com grande propriedade e riqueza de informações como o coletivo de pesquisadores, na linha de pesquisa do Programa de Pós Graduação em Meio Ambiente da Universidade Federal do Paraná (PPGMADE), que ao longo de mais de duas décadas vem se dedicando a este tema.

Nosso esforço está alinhado ao que Dunker (2015) propõe sobre o fato de que há necessidade de se rever a construção dos paradigmas que ultrapassem a redução das modalidades de sofrimento a uma mesma gramática normativa, a qual tem se configurado, efetivamente, como uma forma de neutralizar o potencial crítico das populações vulneráveis.

A partir das considerações propostas tentaremos responder duas questões:

- Que aspectos e fundamentos teóricos da subjetividade contemporânea poderão contribuir com a Educação Ambiental Oceanográfica?

- Como construir eixos e pontes nas fronteiras de outras ciências? 
Damos início a esta articulação, partindo, então da concepção de contemporâneo de Agamben, como uma contribuição às respostas sobre as trevas do agora (Agamben, 2009). Isto é o que, em primeiro lugar, já aprendemos com Freud.

\section{AS REGIÕES LITORÂNEAS COMO PALCO DA REPETIÇÃO DE UMA FORMA DE VIDA}

Num sentido histórico mais amplo é fato que as regiões litorâneas brasileiras, no tocante ao meio ambiente, desde o período colonial da nossa história, não preconizaram uma vocação litorânea enquanto uma estrutura territorial, nas esferas político-administrativas. Muito pelo contrário. A forma de ocupação denotou muito mais o aspecto econômico, denunciando desde tal época, a dependência do país em relação aos mercados externos e as ações extrativistas sem reposição, orientadas por um lucro imediato (Moraes, 2000).

Com o passar do tempo esta situação não mudou e as áreas litorâneas brasileiras, em sua grande maioria, continuaram alienadas do conceito de pertencimento vocacional de suas paisagens, ligadas não mais apenas ao mercado externo, mas também às novas formas de expropriação como o turismo, a especulação imobiliária e as atividades portuárias.

A descaracterização da paisagem é um dos resultados mais visíveis deste processo, tendo sido destruída paulatinamente e substituída por empreendimentos imobiliários, turísticos e comerciais de capitalização intensa, expulsando da orla e do interior imediato a vegetação, a fauna e a população humana local; esta última, em sua grande maioria, transformando-se em prestadora de serviços (Nascimento et al., 2017).

Geralmente periféricas aos grandes centros, as pequenas e médias cidades litorâneas da costa brasileira passaram a ter como característica principal uma dispersão espacial, em que o espaço econômico da região também se apresenta desigualmente organizado em termos de produção, circulação e consumo (Moraes, 2000).

A forma de ocupação atual tende a uma estruturação em moldes urbanos, refletida pelas condições de acesso, o reduzido fracionamento dos lotes, e também, 
mais recentemente, pelas novas modalidades de ocupação do tipo condomínios fechados e residências coletivas. ${ }^{3}$

Atraindo investidores e novos moradores para estas modalidades de ocupação, a população sai em busca de trabalho e renda, acentuando-se as interdependências e distâncias sociais entre os que compram os imóveis e os que trabalham na sua construção ou prestam serviços aos compradores. Assim, trabalhadores e suas famílias permanecem na região erguendo barracos nos bairros afastados, adensando a população em áreas desprovidas de infraestrutura básica.

A paisagem natural, com boa qualidade de ar, água, biodiversidade e de grande beleza cênica provoca que os investidores privados intensifiquem sua ação comercial, industrial e de serviços, originando, além da expansão da intervenção humana, inúmeros problemas para a administração pública: abastecimento de água, rede de esgotos, coleta de lixo, conservação de ruas e estrada, de tal modo que o que foi vendido como qualidade ambiental se transforma em deterioração (Moraes, 1998).

Este cenário oportuniza a grande desigualdade entre aqueles mais vulneráveis e os mais ricos, fato que, sob a interação com o ambiente natural de maneira predatória, estabelece um quadro de alto risco favorável ao desenvolvimento de conflitos bem como engendrando 0 processo de desaparecimento dos modos de vida antigos. Mesmo nas porções menos povoadas, regiões tradicionalmente ocupadas pelas comunidades de culturas e modos de vida tradicionais, há uma significativa imposição por um modo de vida, de caráter eminentemente neoliberal ${ }^{4}$.

\footnotetext{
${ }^{3}$ Referimo-nos ao livro de Cristian Dunker "Mal Estar, Sofrimento e Sintoma- uma psicopatologia do Brasil entre muros" sobre a privatização do espaço público que transforma a própria vida em formas de condomínio, com seus regulamentos, síndicos, gestores e muros (Dunker, 2015).

${ }^{4}$ A origem do conceito de neoliberalismo apresentado por Friedrich Hayek em seu texto "O Caminho da Servidão", em 1944. Este texto é literalmente configurado como um ataque ao Estado intervencionista e de bem-estar social, contra qualquer limitação dos mecanismos de limitação de mercado por parte do Estado, denunciado como uma ameaça letal à liberdade, não somente econômica, mas política (Cesar Junior, 2010). Dunker (2016) aponta que há frequente confusão na limitação do neoliberalismo como apenas o conjunto de práticas que definem o capitalismo contemporâneo em sua capilaridade globalizada e que isso, dificultaria o trabalho de circunstanciar críticas e analisar problemas locais, tornando as objeções ao neoliberalismo como o enfrentamento de um inimigo mais poderoso do que ele realmente é. Por outro lado, continua o autor, há problema inverso, ou seja, o seu subdimensionamento à apenas uma teoria econômica, nascida nos anos 1930 O psicanalista propõe que, nesta zona intermediária, entre uma etapa difusa do capitalismo e uma teoria econômica bem definida, que o neoliberalismo seja considerado como uma forma de vida, pois compreende uma gramática de reconhecimento e uma política para o sofrimento.
} 
Adicionalmente há o grave cenário da poluição dos oceanos. Mesmo que exista um apelo emotivo de significativa parte da sociedade civil organizada que busque gerar uma comoção ampla, principalmente em relação a fauna e flora dos ambientes marinhos, a perspectiva é negativa, numa expectativa futurística de 150 milhões de toneladas resíduos - algo que em breve ultrapassaria o peso de todos os peixes nos mares ${ }^{5}$. Salientamos, no entanto, que a poluição é apenas mais um aspecto que a Educação Ambiental em ambientes marinhos deve levar em consideração. Em fato, são as evidentes contradições das grandes corporações que, se por um lado realizam campanhas de minimização de impactos e reciclagem, por outro continuam a realizar os lobbys milionários para invalidar projetos de lei contra os plásticos ${ }^{6}$. Neste aspecto torna-se óbvio, parece-nos, que a escassez dos bens marinhos tenda somente a aumentar, consolidando o desaparecimento das comunidades tradicionais que têm suas vidas mantidas por estes recursos.

No litoral paranaense não tem sido diferente. Além dos aspectos de degradação ambiental, o histórico de ocupações irregulares, a existência de conflitos e injustiças ambientais ${ }^{7}$, configura o que definimos como sintoma $^{8}$, numa homologia proposta por Farias (Farias, 2017; Farias e Knechtel, 2018) ao conceito freudiano de mesmo nome.

O litoral paranaense, rico em remanescentes de Floresta Atlântica, manguezais, restingas, estuários e baías, paisagem natural de alta complexidade ambiental de grande importância para a reprodução e biológica, possui significativas potencialidades econômicas ainda não completamente dimensionadas. Cenário com grande número de famílias coletoras, extrativistas, de agricultores e pescadores que tradicionalmente vivem da utilização e comercialização destes recursos.

A ocupação intensa e extensa dos balneários paranaenses, tal como em outras regiões da orla brasileira, tem conflitos relacionados à especulação imobiliária, uma atividade com amplitude maior que as próprias dinâmicas turísticas.

\footnotetext{
5 Sugerimos os excelentes documentários Oceanos de Plástico (https: //www.youtube.com/watch?v=5ginrbbkPcA) e Trashed (htps: //www.youtube.com/watch?v=7UM73CEvwMY).

${ }^{6}$ https: //theintercept.com/2019/07/28/como-industria-plasticos-luta-para-continuar-poluindo-o-mundo/ A reportagem fundamenta seus argumentos a partir de artigos científicos, realizando uma importante critica às incongruências da indústria de plásticos. Numa outra perspectiva é possível encontrar informações trazidas pela Organização das Nações Unidas através da Campanha Mares Limpos.

${ }^{7}$ Aspectos fundamentados no excelente trabalho realizado pelos doutorandos da linha do Costeiro através da oficina Coletiva, realizada em 2017 (NASCIMENTO et al., 2017).

${ }^{8}$ Fenômeno subjetivo que constitui, para a psicanálise, não o sinal de uma doença, mas a expressão de um conflito inconsciente.
} 
Como consequência há não somente um distúrbio dos ambientes naturais devido às ocupações em áreas frágeis ambientalmente, mas também em relação à prestação de serviços por parte dos agentes públicos, que acabam por não obedecer à demanda social, mas a interesses particulares dos agentes imobiliários (Andriguetto Filho, 2004; Faraco et al., 2006; Pierri et al., 2006; Azevedo, 2016; Nascimento et al., 2017). A contaminação dos recursos hídricos, seja por esgotos domésticos e lançamento de resíduos nos cursos d'água, seja de origem das abrangentes atividades portuárias, torna-se comum.

A pesca é uma parte importante da economia local, onde pescadores distribuem-se em vilas, rurais ou urbanas e, mesmo sendo pouco expressiva economicamente, é relevante por envolver parte importante da população e produzir alimento. Nesse sentido ainda, as diversas comunidades praticam diferentes sistemas produtivos, desde formas mais tradicionais às mais tecnificadas (Nascimento et al., op.cit.).

No tocante aos conflitos e injustiças ambientais no litoral paranaense também são as comunidades tradicionais que sofrem as consequências, como detalha 0 trabalho de Cherem e Azevedo (2016). Na sua grande maioria se tratam de disputas de ordem fundiárias, relacionadas às populações locais e as áreas destinadas às Unidades de Conservação, ao uso balneário/turístico e pela expansão portuária, além da própria especulação imobiliária nestes casos.

As autoras descrevem casos envolvendo desde coação, através da aplicação intensiva de multas por parte dos órgãos responsáveis, até ameaças de morte aos integrantes que se recusam a sair de suas áreas tradicionalmente ocupadas.

A construção acima confirma nosso pensamento que não há algo de novo nas condições de degradação socioambiental nas regiões litorâneas, mas sim alguma coisa da ordem de um caráter histórico, que se reproduz continuamente, o que do ponto de vista psicanalítico é uma manifestação da natureza pulsional do processo civilizatório (Farias e Knechtel, 2018) ${ }^{9}$.

Reconhecemos, deste modo, que as questões socioambientais no âmbito das regiões marinho-costeiro, mesmo possuidoras de particularidades em termos de paisagens e configurações territoriais, estão alienadas a uma forma de vida - a

\footnotetext{
${ }^{9}$ Freud define pulsão, em 1915 na obra As pulsões e seus destinos enquanto um "estímulo para psíquico (Freud,1914-1915/2013: 17)". Freud ainda marca que este é um conceito que se situa na fronteira entre o psíquico e o físico, diferente de instinto, com o qual é usualmente associada, e, portanto não tem por finalidade manter a vida, ou a auto conservação
} 
capitalista - que constitui os modos de subjetividade, formas de trabalho, de desejo e linguagem, como expõe Safatle acerca do horizonte capitalista (Safatle, 2019: 04).

Numa observação crítica, este conjunto de elementos, ou seja, as questões históricas, a conformação atual das paisagens segundo os modos de apropriação pelo poder hegemônico e os consequentes desastres, tragédias ambientais, vemos confirmar como a nossa história ambiental é sustentada pelos excessos de um sistema econômico, denunciando que os bens naturais não são extraídos a partir de uma necessidade finda com a satisfação ou com o consumo destes em si mesmos. Ao invés disto, desvelam um processo essencialmente sem limites, onde não espaço para o reconhecimento da finitude do ambiente tampouco para a alteridade ou qualquer coisa que direcione à construção e/ou fortalecimento dos laços sociais.

Portanto, vemos como é importante que nesses cenários de subalternidade, os sujeitos ressignifiquem suas experiências em relação aos aspectos socioambientais, singularizando-as, enquanto um reconhecimento de possibilidade de mudança destas mesmas condições.

Observemos isto melhor na sequência.

\section{A SUBJETIVIDADE CONTEMPORÂNEA QUE ENLAÇA A REALIDADE SOCIOAMBIENTAL}

(...) remexeram no fundo do mar, a gente conhece o fundo do mar, sabe que se mexer do jeito que eles fizeram vai matar filhote de peixe, você veja, mais de 60 caminhões de lama eles tiraram, a gente viu. Garantiram pro pescador que nada ia acontecer, mas como que não vai acontecer nada? Não somos contra o Estado, mas mentir desse jeito pra nós, aí não! Acabaram com o nosso mar". ${ }^{10}$

Diante do exposto vemos que as questões territoriais, tipos de uso e ocupação, dizem menos das causas naturais, mas sim evidenciam uma forma de vida - capitalista - a que os sujeitos estão submetidos, uma configuração de vida que tem consequências sobre o modo de sofrimento dos sujeitos.

Sob este aspecto podemos observar dois pontos interessantes do ponto de vista prático. Primeiro, os diagnósticos que tem como consequência articular propostas para implantação de projetos a partir da visão de uma Educação Ambiental crítica, necessitam observar que o sofrimento gera efeitos múltiplos

\footnotetext{
${ }^{10}$ Recorte da fala de um pescador retirado do artigo de Cherem e Azevedo (2016: 24).
} 
quando falamos de comunidades expostas a um sistema de opressão. O exemplo mais contumaz é o de Belo Monte, como descrevem Dunker e Fragelli (2018) reforçando o que um dos autores já havia dito sobre ser "importante jamais separar o sofrimento individual dos movimentos sociais Ihes deram origem (Dunker, 2015: 36)".

Em segundo, propostas da Educação Ambiental que tenham como objetivo único "ensinar cognitivamente" sobre conservar os bens naturais não atendem, por si só, a necessidade de transformação que precisamos frente a complexidade das questões socioambientais da era moderna, como bem descrevem Layrargues e Lima (2014):

(...) Educação Ambiental Crítica tende a conjugar-se com o pensamento da complexidade ao perceber que as questões contemporâneas, como é o caso da questão ambiental, não encontram respostas em soluções reducionistas. (...) Por essa perspectiva complexa torna-se não só possível como necessária a incorporação das questões culturais, individuais e subjetivas que emergem com as transformações das sociedades contemporâneas, a ressignificação da noção de política, a politização da vida cotidiana e da esfera privada, expressas nos novos movimentos sociais e na gênese do próprio ambientalismo (Layrargues e Lima, 2014: 33).

Num nítido alinhamento ao pensamento dos autores acima acreditamos que, em situações de vulnerabilidade socioambiental, como no caso das regiões costeiras, a Educação Ambiental deve também legitimar as ações que tratam de fazer emergir a voz das comunidades tradicionais que se encontram emudecidas, configurando o que se denomina de 'invisibilidade ambiental', um neologismo ou arranjo de palavras necessário diante do que ainda precisamos reconhecer e nomear.

Nesta condição - de vulnerabilidade - o pertencimento e a submissão no campo da apropriação da natureza também são condicionados pelo poder hegemônico, que naturaliza o desamparo social e apaga a força discursiva dos que estão sob este processo de opressão ${ }^{11}$. Uma dimensão que atua na constituição dos

\footnotetext{
${ }^{11} \mathrm{O}$ trabalho de Toledo e Gasparini (2015), em relação às consequências dos conflitos acerca do uso e ocupação do solo na Comunidade de Amparo, área de proteção ambiental situada na Baía de Paranaguá, sob este aspecto, consubstanciam a nossa reflexão. Dizem os autores: "cabe salientar a importância de se desenvolver projetos que tenham em mente o resgate da autoestima dessas populações (...).O que ficou evidenciado no decorrer do trabalho é que, em relação às comunidades pesqueiras que secularmente habitam unidades de conservação, como no caso em apreço, os parâmetros sociais, atualmente indissociáveis da questão ambiental, ficam em segundo plano, fato que implica o distanciamento das pessoas de suas tradições, na fragilização de sua identidade, em mudanças em suas cosmologias e cosmovisões, em problemas relacionados à sua subsistência, à
} 
sujeitos, advinda, portanto, de estratégias políticas para destituir o lugar que estes possuem no tecido social.

Desta forma, os sujeitos, desenraizados de si, num desconhecimento enigmático do desejo e sua ignorância, seguem sem compreender a sua participação na produção dos fenômenos que os atingem. De uma maneira bastante simples, traduzimos este fato como a dificuldade em que os sujeitos têm em associar as suas próprias questões com aquilo que é erigido contra eles, pelo modelo econômico vigente, e que estabelece o seu contexto de desamparo social.

São estas comunidades, portanto, que habitando historicamente estas regiões, delas retirando seu sustento, possuindo laços importantes com a paisagem local, carecem ser ouvidas e acolhidas a partir de seus afetos, além de seus saberes, tomando como exemplo o que foi feito na Clínica da Escuta de Belo Monte, a ser detalhado mais adiante. Ou ainda, sob outra abordagem epistêmica, o trabalho desenvolvido por Losekann (2017), acerca do qual também descreveremos posteriormente.

Sob esta concepção caberia perguntar acerca de quais seriam as consequências subjetivas que irão marcar os sujeitos, em especial, nessas comunidades tradicionais, submetidas à forma de vida capitalista, mas esta é uma questão para qual ainda não temos respostas.

De toda a forma, podemos, tentativamente, circunscrever duas perspectivas: a violência psíquica que origina um sofrimento e a época contemporânea, que sob os auspícios do neoliberalismo se ancora numa certa melancolia - em termos de Safatle (2017) - induzindo a uma inação, qual impossibilita os sujeitos a reagirem perante isto que os oprimem.

Prossigamos.

\section{A violência e o sofrimento}

Para esta discussão vamos olhar as comunidades tradicionais inseridas na paisagem do litoral do Paraná, ambiente em que podemos perceber, sob um olhar

segurança alimentar e nutricional, em suas condições de vida e relacionamento interpessoal, consubstanciando-se em um lento processo de degradação que tolhe as perspectivas de vida e de futuro dessas comunidades, impingindo-os ao êxodo e à migração para os centros urbanos (neste caso, a cidade de Paranaguá) (Toledo e Gasparini, 2015: 30). 
mais atento, às nuances que desvelam componentes desta subjetividade contemporânea.

O cenário de dificuldade crescente no desenvolvimento das atividades econômicas dessas comunidades se origina por fatores diversos que acabam por atuar sinergicamente: a escassez ampliada dos recursos, as restrições ambientais quanto ao uso do solo e dos bens naturais bem como o atrelamento a uma atuação do poder público, em oposição aos mais vulneráveis (Rainho, 2015; Cherem e Azevedo, 2016; Nascimento et al., 2017).

Mas é pela fala dos próprios moradores locais que se percebe a denúncia das situações de violência psíquica. Em sua grande maioria esta é a condição que os leva, consequentemente, a uma migração forçada, especialmente rumo às periferias e favelas de Paranaguá, numa incapacidade de fazerem valer seus direitos e saberes tradicionais sobre o ambiente que habitam. Migrar, nesses casos, deixa uma marca, de registro simbólico, visto que não se trata de deixar somente aquilo que era o seu objeto de trabalho, mas também um ambiente que percebem cada vez mais ameaçados seja pelas grandes empresas ou mesmo pelo poder público que não os protege nem a sua história e a de pessoas queridas. Enfim, tudo o que é componente da estrutura dos seus laços sociais.

Um caso que entendemos ser importante contemplar é o da comunidade tradicional de Barra do Ararapira, distrito localizado no município de Guaraqueçaba, litoral norte do estado do Paraná. A perspectiva da violência - neste caso eminentemente imposta pelo Estado - se expressa na imputação das consequências da criação de uma Unidade de Conservação, o Parque Nacional de Superagui, que passou a lhes impor restrições sobre suas práticas produtivas e culturais, como a proibição das roças e as extrações na mata, passando a ditar as suas histórias por uma política ambiental excludente, embasada no ideal de natureza intocável, como expõe Rainho (2015: 20). Neste caso, diz-nos a autora, o Parque acaba representando uma política governamental que apenas repete a história, reprimindo e excluindo povos que sempre foram marginalizados, limitando-os uma única forma de manejar a natureza. Vejamos um recorte de fala sobre isto:

O que um cara sentado no escritório sabe? Eles só veem foto de satélite. A gente sabe prever o tempo, a gente sabe quando a água está boa para peixe. Eles não têm o conhecimento que a gente tem. A gente sabe por experiência. A força verde considera a gente bandida. Não temos voz, não temos autoridade nem para pegarmos nossas redes de volta. Era pra 
sermos aliados deles e não inimigos. O que eles fazem conosco é humilhante! Edivaldo, entrevista dia 11/07/2014 (Rainho, 2015: 156).

A fala do morador, nitidamente, delata a imposição de um tipo de circulação, não somente de bens, mas de valores, que desconsidera os moradores na dinâmica social em que já estavam inseridos. Numa reflexão continuada, percebe-se que há uma perversidade na lógica de circunscrever territórios à custa dos corpos de outros, negando a sociabilidade destas comunidades, ou seja, tratando-os como anônimos e sem rostos.

No caso de Ararapira, a violência infligida se associa aos desafios da natureza inóspita, pois a comunidade sofre os impactos da erosão, um agente geológico que atua com a dinâmica costeira. Ressalta-se, a partir da explicação de Muller (2007) que as características das ocupações tradicionais, do ponto de vista físico, não agridem a linha de costa e não comprometem o balanço sedimentar das praias, diferentemente de ocupações urbanas típica, com avenidas e calçadões à beira mar, contrariando neste aspecto, alguns dos motivos da ação restritiva do Estado.

Sob esta ótica, vê-se a dupla violência, ou seja, não somente aquela advinda do Estado, materializado pelo órgão ambiental, que os leva a serem vistos como "aqueles" que devem ser expulsos do Parque assim como a exclusão pela própria dinâmica natural do ambiente.

Em relação ao papel do Estado, neste caso, Freud já havia apontado para esta incongruência no Mal-Estar da Civilização em que se diz "não podendo compreender por que as instituições por nós mesmos criadas não trariam bem-estar e proteção para todos nós (Freud, 1930/2010: 44)". Portanto, sob esta lógica é pertinente que, se ponha uma questão aí, acerca de quem ou o quê deveria cuidar e proteger estas comunidades.

Numa outra abordagem epistêmica, mas que aqui apresentamos com o fim de trazer mais elementos para nossa exposição, a violência atinge as comunidades tradicionais num processo repetição que nos faz reafirmar não ser da ordem de um contingente, mas consequência da forma de vida no horizonte capitalista.

Este é o caso das comunidades que foram atingidas por algo que nunca sequer poderiam ter imaginado, como Losekann (2017) nos mostra ao discorrer sobre daqueles que foram submetidos ao impacto da lama tóxica, no Espírito Santo, resultante do rompimento da barragem de Fundão, ocorrido em Minas Gerais. A 
chegada se deu após 11 dias do ocorrido, mais precisamente no dia 11 novembro de 2015 no município de Guandu, espalhando-se dia após dia, em todo o território do Estado, até desaguar no Oceano Atlântico, onde o ambiente natural se corrói numa lenta assimilação mortífera, indefinidamente ${ }^{12}$. A autora relata que os moradores das cidades de Baixo Guandu, Colatina, Linhares, Aracruz e São Mateus, região litorânea do Espírito Santo, nunca poderiam sequer ter imaginado que seriam abalados, algum dia, por uma barragem de rejeitos localizada a uma distância de aproximadamente $600 \mathrm{~km}$, que até então nem sabiam que existiam. Como um elemento suplementar, a relação histórica ${ }^{13} \mathrm{com}$ minério de ferro fortaleceu a conexão, gerando diferentes maneiras de afetação, desde uma grande ansiedade, pela expectativa da chegada da lama tóxica, a tristeza da constatação do desastre, o luto pela evidente perda de locais queridos até indignação e revolta.

Ora como já apontamos em Rainho (2015), Cherem e Azevedo (2016) e Losekann (2017) ao longo desta exposição, vê-se como elementos pouco perceptíveis da nossa afetividade (como a raiva, a ira, a alienação, a dor) estão presentes não somente em grandes desastres, mas também no cotidiano daqueles que estão submetidos a um cenário opressivo. Além disso, tudo o que o próprio conceito de lei deveria nos remeter, a saber, a reciprocidade, o reconhecimento e a alteridade, acabam sendo completamente distorcido ou mesmo ignorado.

São estas circunstâncias, portanto, que contribuem para que os indivíduos se tornem emudecidos e, consequentemente, retirem-se do espaço político, visto que estão em grande sofrimento psíquico. Tornam-se nítidas, assim sendo, as consequências do predomínio de uma gramática pautada pela matriz econômica neoliberal que materializa a violência, na consequente aceitação de que a dor que se instaura nas comunidades, desde a concepção até a implantação de projetos para o nosso desenvolvimento, é algo natural.

Mas como compreender essa violência?

\footnotetext{
12 É importante lembrar sobre a explosão do navio Vicunha, em 2004, onde quatro tripulantes morreram e toneladas de óleo foram derramadas na baía. A empresa foi condenada por danos ambientais e a pagar indenização aos pescadores e famílias indígenas da área, que perderam o alimento e o sustento. No entanto não encontramos referências específicas sobre como as consequências em deste desastre ambiental se deram nas comunidades tradicionais e os seus modos de vida.

${ }^{13}$ Isso se deve ao fato de a maior parte do minério de ferro extraído em Minas Gerais ser transportada através de Espírito Santo para exportação através de portos deste estado, tendo sido inaugurado o principal porto em 1966. Acima de tudo, as pessoas afetadas por esse desastre viviam lado a lado com trens que transportam minério de ferro diariamente em vagões abertos.
} 
A violência acontece, diz-nos Birman (1996), porque há uma onipotência dos opressores que acreditam poder impor seus ideais e instituir a sua lei, sem reconhecimento da singularidade e nem a diferença do oprimido, onde inexiste o dom e trocas, que marcam profundamente a experiência psíquica. Trata-se de uma relação em que há um sujeito que, segundo o autor:

\begin{abstract}
"se autoriza a tirar as coisas dos outros quando queira e arrancá-las pela violência eminentemente predatória", tal qual um objeto a ser usufruído, sem reconhecimento da alteridade desse outro, destituído então da sua singularidade ," delineado, pois, como um pedaço de carne à disposição" do sujeito, para que esse possa manipulá-lo e instrumentalizá-lo para as delicias macabras do seu gozo, já que aquele detém os bens e os objetos que atiçam a cobiça voluptuosa do sujeito. (Birman, 1996: 125).
\end{abstract}

Birman nesta afirmação, desvela a potência da intimidação, algo da ordem de uma irrupção, que acaba por violar limites, suspendendo o pacto simbólico, inclusive do corpo, dos recursos da fala, anulando o laço e o endereçamento ao outro. Vejamos ainda que há aqui uma diferença importante a ser delimitada entre dor e sofrimento, como compreende Nasio (1997) que, numa expressão de beleza comovente, diz-nos que:

(...) antes de tudo, a dor é um afeto, o derradeiro afeto, a última muralha antes da loucura e da morte. Ela é como um estremecimento final que comprova a vida e o nosso poder de nos recuperarmos. Não se morre de dor. Enquanto há dor, também temos forças disponíveis para combatê-la e continuar a viver (Nasio, 1997: 23).

Num contraponto, o sofrimento é aquilo que ainda não conseguimos colocar em palavras, ou melhor, algo que nos acomete e que é, de certa maneira, mal apreendido, que escapa à razão, sendo importante sua elaboração simbólica.

Nasio (op.cit) nos diz que não se trata apenas de propor uma interpretação forçada da sua causa, nem mesmo de consolar o sofredor, e menos ainda estimulálo a atravessar sua pena como uma experiência formadora, que fortaleça o seu caráter. A violência e o afeto da dor, enquanto um limite que decorre das injustiças e conflitos socioambientais antes de tudo precisa ser nomeado, ou melhor, que lhes seja possível Ihes dar sentidos, simbolizá-los, permitindo que àqueles que sofrem possam contar a sua história, a partir da realidade incerta, desvencilhando-se da penosa incumbência de reconstituição compulsiva de um passado idealizado ou de um futuro sonhado.

Os sujeitos atingidos pelas consequências da degradação ambiental (degradação entendida também no sentido ético) devem ser ouvidos para que haja um afinamento com sua dor, construindo um lugar no seio da sociedade, da nossa 
história e que esse sofrimento não seja efetivamente considerado como apenas uma palavra impressa em processos decisórios.

Num correlato às questões socioambientais, concordamos com Maria Rita Kehl, psicanalista, integrante da Comissão Nacional da Verdade ${ }^{14}$ (2009), quando se refere às consequências que até hoje a sociedade brasileira sofre dos efeitos da repetição da violência social, sucedidos por conta dos três séculos de barbárie escravagista, entre os séculos XVII e XIX, e duas décadas de ditadura militar, entre 1964 e 1985, como episódios de crueldade, os quais nunca foram reparados nem elaborados coletivamente. Kehl aponta as consequências desses fatos:

São "inconscientes" em uma sociedade", tanto as passagens de sua história relegadas ao esquecimento quanto as expressões silenciadas de minorias cujos anseios não encontram meios de se expressar. Excluído das possibilidades de simbolização, o mal-estar silenciado acaba por se manifestar em atos que devem ser decifrados (Kehl, 2009: 25).

$\mathrm{Na}$ posição da autora expressa acima, vemos um alinhamento ao pensamento de Vladimir Safatle (2017) - que discutiremos a seguir - e ao de Miriam Debieux Rosa (2016), sobre o emudecimento daqueles excluídos do bem-estar social, colocados, que estão, na condição de objeto e não de sujeito.

Se esta é uma configuração da nossa época é lícito e urgente entender o que causam às comunidades tradicionais e para isso é preciso circunscrever um campo mais amplo, que se traduz uma espécie de economia psíquica do poder, como veremos a seguir.

\section{A contemporaneidade melancólica nas questões socioambientais brasileiras}

A partir do que colocamos acima vamos avançar um pouco mais para compreender os afetos que enlaçam os que estão a sofrer as consequências da injustiça ambiental.

Vladimir Safatle (2017) propõe que a sociedade atual passa por um processo de melancolização, no sentido do conceito freudiano, que reflete a inatividade da nossa capacidade de imaginação política'15. A partir do livro 'Mecanismos psíquicos do poder', de Judith Butler, Safatle (op.cit) vislumbra uma espécie de economia

\footnotetext{
${ }^{14}$ Colegiado instituído pelo governo do Brasil em 2012 para investigar as graves violações de direitos humanos ocorridas entre 18 de setembro de 1946 e 5 de outubro de 1988. As violações aconteceram no Brasil e no exterior, praticadas por "agentes públicos, pessoas a seu serviço, com apoio ou no interesse do Estado" brasileiro.

${ }^{15}$ Café Filosófico: https: //www.youtube.com/watch?v=LLLxyYgWzQA.
} 
psíquica do poder ou política da psique, com a qual faremos um correlato com as questões socioambientais.

Para compreender a que isto se refere, inicialmente mostramos a diferença entre luto e melancolia visto que as duas situações não se referem a perdas que podem ser vistas da mesma forma. Freud situa que as duas categorias são semelhantes nas suas características gerais tais como a dor, o desânimo e a apatia, uma sensação de pesar e a perda de interesse pelas coisas relacionadas ao mundo, todas elas oriundas de uma falta, ou seja, um objeto que fora amado e que agora não mais existe (Freud, 1915/2011).

No entanto, as diferenças são perceptíveis e importantes, pois se no luto há uma luta em que o sujeito busca não sucumbir, mas sim reagir; no caso da melancolia, a dor pela perda é tão profunda que torna o indivíduo inábil, incapaz de produzir qualquer simbolização, ficando o $E U^{16}$ remetido ao imenso vazio, completamente indisponível a investimentos externos.

Nasio (1997), em sua interpretação sobre o tema, sustenta que existe a possibilidade de um indivíduo ficar paralisado durante toda a vida, caso o luto se torne obstinado, como podemos ver:

\begin{abstract}
Compreende-se então que se esse trabalho de desinvestimento que deve seguir-se à morte do outro não se cumprir, e se o eu ficar assim imobilizado em uma representação coagulada, o luto se eterniza em um estado crônico, que paralisa a vida da pessoa enlutada durante vários anos, ou até durante toda a sua existência. (Nasio, 1997: 29).
\end{abstract}

De fato, o autor entende que há tal processo de apego ao objeto perdido que o sujeito sucumbe, paralisando sua vida, apontando ainda que há rebaixamento da autoestima do melancólico, em virtude de um empobrecimento do seu EU, colocando-se num lugar de alguém incapaz, indigno e desprezível, rejeitando-se e, muitas vezes se castigando.

A teoria da melancolia repercutiu no pensamento freudiano de tal forma que, no mesmo ano da sua elaboração, Freud escreve textos como 'Considerações atuais sobre a guerra e a morte', uma investigação filosófico-científicas sobre a desilusão (melancólica) que a Primeira Guerra trouxe para os habitantes das supostas civilizações evoluídas do Ocidente, como observa Kehl (2011).

\footnotetext{
${ }^{16}$ EU: sede da consciência e também lugar de manifestações inconscientes; o eu, elaborado por Freud em sua segunda tópica (EU, ISSO E SUPEREU), é uma diferenciação do isso; é a instância do registro imaginário por excelência; portanto, das identificações e do narcisismo (Chemana, 1995: 64).
} 
Sob a ótica do poder, ponto que nos interessa enquanto uma fronteira da Educação Ambiental, o pensamento de Safatle (2017) se oferece para que vejamos as consequências de um processo de melancolização, que inclui a internalização de um princípio de autocontrole, tal qual a ideia de um estado policial dentro de si, permitindo que o 'poder externo' atue não mais fisicamente, mas sim de maneira interna aos indivíduos. Mas, segundo Safatle, o que de fato se interioriza não seria exatamente o que se tem como melhor, aquilo que está em prol do bem comum de todos, mas sim um afeto produzido pela lembrança contínua do vínculo a um objeto que se perdeu, a um ideal, a uma promessa.

É neste instante, então, que a resignação contínua se instaura, originando uma percepção de que tudo o que já havia sido tentado é da ordem de um fracasso, assim como todos os investimentos até então realizados.

O modelo de coesão social, de adesão, de aquiescência às normas transmite, de certa forma, que qualquer coisa que acontecer de diferente será pior ${ }^{17}$. Gerando, enquanto vínculo social, um afeto melancólico que, última instância, revela-se na impotência, na inação, na apatia. Os sujeitos olham para si mesmos e, tal como uma sombra que cai sobre si, se vêm marcados pela impotência, bloqueando toda e qualquer imaginação política.

Observando com mais cuidado outros autores, vemos como o pensamento da psicanalista Miriam Debieux Rosa está alinhado ao de Safatle (op.cit), acerca das consequências do modelo neoliberal daqueles em situação de pobreza extrema e da exclusão social, como a autora expressa:

\footnotetext{
${ }^{17}$ Isto nos remete também a retórica paranoica do discurso neoliberal à qual a análise de Dunker (2016), afirma que existe uma retórica do perigo, como se a civilização estivesse sob estado de ameaça, sob ataque constante, algo da ordem do "estamos à beira de uma crise, há necessidade de reformas, precisamos fazer alguma coisa“. Ora, não é essa a retórica usual na defesa do desenvolvimento em detrimento das questões ambientais brasileiras, ou seja, 'a de que precisamos de mais empregos, precisamos de alimentos, precisamos de crescimento econômico?' de forma a colocar num antagonismo permanente proteção ambiental e a qualidade de vida das pessoas? As reflexões de Dunker seguem apontando que há uma frequente confusão na limitação do neoliberalismo como apenas o conjunto de práticas que definem o capitalismo contemporâneo em sua capilaridade globalizada e que isso, dificultaria o trabalho de circunstanciar críticas e analisar problemas locais, tornando as objeções ao neoliberalismo como o enfrentamento de um inimigo mais poderoso do que ele realmente é. Por outro lado, continua o autor, há problema inverso, ou seja, o seu subdimensionamento à apenas uma teoria econômica, nascida nos anos 1930.0 psicanalista propõe que, nesta zona intermediária, entre uma etapa difusa do capitalismo e uma teoria econômica bem definida, que o neoliberalismo seja considerado como uma forma de vida, pois compreende uma gramática de reconhecimento e uma política para o sofrimento. (Dunker, 2016). Disponível em: https: //www.youtube.com/watch?time continue=860\&v=3noUnc0emC8 Acesso em 28 de agosto de 2019.
} 
(...) é a apatia, a solidão, o emudecimento, assim como a reprodução, na subjetividade, da violência e da pobreza afetiva e intelectual , como encobridoras da possibilidade de elaboração simbólica que poderia dar forma sintomática ao que é vivido como traumático (Rosa, 2016: 43).

A psicanalista nos coloca claramente que o sujeito se cala pela condição de um impacto traumático, ao se sentir notoriamente impotente diante da rigidez do Outro $^{18}$, ou seja, aquele que lhe barra o acesso a uma condição de desejante.

Interessante notar que Rosa (op.cit) avança dizendo que, se desta forma se constrói uma barreira, ou mesmo uma suspensão temporária, situação que pode se estender durante uma vida inteira, isto não seria estrutural, mas um modo de resguardo ante a posição de resto na estrutura social. "Uma proteção necessária para a sobrevivência psíquica, uma espera, uma esperança," conclui (Rosa, 2016: 43) $)^{19}$.

A visão da psicanalista, portanto, mais uma vez vem ao encontro do que Safatle (2017) entende sobre a existência de épocas em que toda uma população entra em paralisia, configurando uma espécie de patologia social, perdendo a crença na sua própria capacidade de produzir saídas e alternativas.

Por isso, a compreensão de Rosa (op.cit) afirmando que estas situações não são estruturais, portanto, passíveis de mudança, as torna ainda mais significativas e interessantes na articulação com a Educação Ambiental. Parece-nos que as situações de resistência, como a citadas nos itens anteriores, denunciadas pela fala dos pescadores, confirmam esta possibilidade e merecem, certamente, uma investigação mais detalhada na tentativa de responder às seguintes questões: quais elementos subjetivos da condição dos indivíduos destas comunidades, que mesmo ante uma economia psíquica melancólica, marcada pelo trauma da violência,

\footnotetext{
${ }^{18}$ Grande Outro: entre eu e meu semelhante tem algo presente , que não tem uma substância corporal definida (não é uma pessoa) mas que é ONIPRESENTE em toda a relação entre eu e meu semelhante , que sem essa "coisa" não podemos entrar em contato: é o Grande Outro ( é a linguagem, é o Inconsciente). A linguagem mediatiza o meu encontro com meu semelhante o tempo todo.

${ }^{19}$ Miriam Debieux Rosa traz elementos que nos ajudam a compreender sobre o impacto da violência quando se refere aos adolescentes e imigrantes: "uma psicanálise implicada não é específica para adolescentes ou imigrantes excluídos, mas diz por meio da experiência deles de um modo de laço social que usa as violências, como estratégias de poder, seja para dominar, seja para angariar adesão, pois acena com a possibilidade de salvar-se individualmente do laço perverso e perversor. A perspectiva é de que intervenções nestes casos visem criar condições de alterações do campo simbólico/imaginário -subjetivo, social e político, pois é nessa medida que a psicanálise pode comparecer com elementos para favorecer modos de resistência à instrumentalização social do gozo e a manipulação da vida e da morte no campo social -um terrorismo do ponto de vista do poder soberano (Rosa, 2016: 30)".
} 
permitiram o ecoar das suas vozes? Ou ainda, sob quais circunstâncias isso aconteceu?

Ainda não sabemos responder, mas, todavia, entendemos que isto se associa também a nossa vida política. Sobre isto, Safatle (2017) nos diz que é preciso reconhecer que podemos estar numa época na qual uma das funções fundamentais do poder é nos jogar a uma concepção de vida a que os gregos chamariam de zoé, retirando dos sujeitos o direito a uma vida mais plena, mais realizada, como é a aquela no interior do corpo político ${ }^{20}$.

Desta forma, o poder se constituiria numa estrutura retórica, que se respalda em dar a impressão aos sujeitos que a vida no interior do corpo político é uma vida na qual nenhuma transformação é possível, que é um tempo de repetição infindável e de jogos de interesse.

Na questão ambiental isto é algo rotineiro e pode ser observado na própria divisão das várias correntes dentro da Educação Ambiental, amplamente discutido por Layrargues e Lima (2014). Há uma tendência para discriminar posições políticas, existindo correntes que vinculam as questões ambientais a uma neutralidade inexistente, portanto, retirando a responsabilidade individual e coletiva sobre os processos que nos atingem.

A crítica de Safatle $(2016,2017)$ vem corroborar o que também entendemos ocorrer na relação política com as questões ambientais, impondo uma existência restrita, limitada a uma dimensão da vida animal, um espaço em que a experiência da intervenção política se torna um grande mal. E sob esta ótica o mesmo o espaço de circulação do bem comum aparece como impossível, ou seja, não existe bem comum, pois quando ninguém tem dono, alguém o toma.

\footnotetext{
${ }^{20} \mathrm{Em}$ "O poder soberano e a vida nua", Agamben (2002) trata da questão da vida nua ou comum (zoé) e da vida política ou politizada (bios). É na cultura grega, especialmente em Platão e em Aristóteles, que Agamben se inspira, através dos conceitos de zoé e bios: Zoé é a vida natural, regida pelas normas da natureza e dos instintos puramente animais, livre da cultura, da vontade e da liberdade humana. Bios é uma vida baseada na práxis do sujeito e historicamente elaborada. Segundo Aristóteles, por uma qualidade própria, que é a linguagem, o ser humano passa de zoé a politikòn zôon, isto é, animal político, o que Ihe possibilita uma vida política. Para Aristóteles, o ser humano não ingressa na polis apenas "para viver, mas para a vida boa" e a finalidade última da existência política é a eumeria, o belo dia. A polis, portanto é uma criação racional do ser humano com a única finalidade de proporcionar o bem viver. O "belo dia", porém, jamais se realizou e o motivo do fracasso, segundo Agamben, é a natureza do poder soberano. Na interpretação de Arendt, A "vida boa", como Aristóteles qualificava a vida do cidadão, era, portanto, não apenas melhor, mais livre de cuidados ou mais nobre que a vida ordinária, mas possuía qualidade inteiramente diferente. Era "boa" exatamente porque, tendo dominado as necessidades do mero viver, tendo-se libertado do labor e do trabalho, e tendo superado o anseio inato de sobrevivência comum a todas as criaturas vivas, deixava de ser limitada ao processo biológico da vida.
} 
AMBIENTE \& EDUCAÇÃo

ISSN- 1413-8638

E-ISSN - 2238-5533

v. 24, n. 2,2019

Nesse aspecto, sob o vínculo da melancolia, o espaço de participação política se torna a lembrança da impotência, da incapacidade de transformar, da incapacidade de fazer com que as coisas possam ser de outras formas. Subsequentemente, a estrutura retórica ou gramática neoliberal, como expressa Dunker (2015), faz com que os sujeitos, melancolizados, obscurecidos, acreditem que a sua participação no corpo político de nada irá adiantar.

Vejam que é exatamente o que descrevem Cherem e Azevedo (2016) sobre o modo como as comunidades que utilizam a Baía de Paranaguá para pesca são afetadas pela poluição, por dragagens e fluxo intenso de navios. As autoras se referem especificamente às Ponta Oeste, Maciel e Guapicum, onde existe uma evidente apropriação desses locais seja pelo poder público, atravessadores ou grandes corporações em detrimento dos pescadores, além do fato de lhes serem imputadas as consequências da diminuição ou baixo desenvolvimento de recursos pesqueiros $^{21}$.

Retirado da própria fala dos pescadores (em itálico) evidenciamos alguns pontos: "com muita sujeira de alga verde”, ou seja, a apropriação deixa um 'resto', entendido aqui como a própria poluição; "faz dois meses que ninguém ganha nada”, denotando o processo de exclusão para o acesso aos bens naturais; "estão vivendo do defeso e do bolsa-família", o sentimento de perda da dignidade; "A gente sabe que o país precisa disso, a gente não é contra a modernização", revelando a condição melancólica da resignação.

Claramente percebemos nessas falas que estes sujeitos excluídos do discurso social e, na medida em que o que pensam e sentem não é passível de ser assumido como a sua verdade, avançam numa "sina", sem um caminho para si mesmo, seus filhos, sua comunidade ${ }^{22}$. Situações que nos dizem da necessidade de um redobrado cuidado, pois "a prática psicanalítica mostra que, se por um lado o sujeito pode resistir, sob condições adversas, caso ele encontre brechas na estrutura social para se manifestar, por outro, o posicionamento de apenas um não

\footnotetext{
${ }^{21}$ Reportar-se ao recorte apresentado por Cherem e Azevedo (2016), no início deste item.

22 Pergunta: O senhor gosta de morar aqui? Resposta: Ah, eu gosto mesmo. Só vô saí daqui morto (J, pescador, 53). Pergunta: O que você espera do futuro? Resposta: Olha, pra falá a verdade, o futuro pra mim, eu imagino mais pros meus filho. Não imagino eles aqui... Eu quero que eles terminem o estudo aqui [a vila, na época, tinha uma escola de $1^{\stackrel{a}{a}}$. à $4^{a}$. série] e vão pra cidade termina o estudo. Não quero que eles sejam pescador, de forma nenhuma. Eu vejo o sofrimento de meu marido, é muito sofrida a vida de meu marido... O pescador não tem segurança nenhuma (...) Eu quero que eles estudem pra não sofre o que o pai sofre, né... (K,esposa de pescador, 33)" (Toledo e Gasparini, 2015: 22) .
} 
sustenta uma mudança no laço social" (Rosa, 2016: 45). A conclusão da psicanalista, com a qual concordamos, é que não podemos permanecer apenas nas constatações acerca dos efeitos devastadores da exclusão, mas sim promover modificações nas estruturas sociais e políticas que sustentam esta situação (Rosa, op.cit).

Sob essas circunstâncias é preciso pensar uma Educação Ambiental que não se valha da manutenção de uma posição de inocência e ignorância sobre as determinações de miséria do outro, tentando-se valer-se de um discurso de igualdade ${ }^{23}$, enquanto o que está realmente em questão é a exclusão, a privação dos bens naturais a quem de fato pertence.

\section{SOBRE EIXOS E PONTES NAS FRONTEIRAS DE OUTRAS CIÊNCIAS}

A complexidade que buscamos retratar parece aumentar os desafios da Educação Ambiental, no âmbito das comunidades tradicionais. Desde o início, as nossas interrogações enquanto autoras se direcionaram para compreender 0 cenário de degradação socioambiental, não somente no que tange aos aspectos físicos, mas também aqueles pertinentes à ética, à (in)justiça, que se expande num crescente e as consequências sobre aqueles que são atingidos pelos eventos traumáticos decorrentes. Infelizmente, no Brasil, sabemos que a lei está completamente dissociada das práticas sociais de justiça, como já havia dito Birman (1996).

Todavia, ao percorrer este caminho, vimos que não há mais como desconsiderar a dimensão de sofrimento que se instaura na estrutura psíquica dos sujeitos submetidos à injustiça ambiental. Quando pensamos nas comunidades tradicionais percebemos, através estudos já existentes, um reconhecimento de que algo escapa a nossa concepção tradicional, que desvela, no contexto da injustiça ambiental, uma demanda de trabalho conjunta com a Educação Ambiental eminentemente crítica.

\footnotetext{
${ }^{23}$ Referência ao trabalho de Andrea Zhouri et al. (2016) numa alusão a estratégia imposta pela empresa Samarco (Vale/BHP-Billiton) de ressignificar as vítimas como como partes interessadas, o que permite com que ela mesma, enquanto ré, também seja ressignificada da mesma forma. Isto, de certa forma, ocasiona , portanto, o apagamento das próprias vítimas.
} 
Tentamos mostrar que surgem cada vez mais autores brasileiros, a exemplo de Zhouri et al. (2016), Losekann (2017), Giongo (2017) ${ }^{24}$ se dedicando a esta temática, ou seja considerando as questões subjetivas que envolvem o amplo espectro do meio ambiente, oferecendo possibilidades de se pensar novas formas de resistência, sejam elas formais ou não, individuais ou coletivas.

Assumindo que esta ponte, portanto, ainda está em processo de construção, trazemos um exemplo de trabalho que pode ser orientativo na materialização de uma proposta, sob a perspectiva da Educação Ambiental Oceanográfica Socioambiental.

Vamos a ela.

Clínica da Escuta em Belo Monte ${ }^{25}$

A partir de um grupo de voluntários da área de psicanálise foi criado um projeto, com recursos a partir de um crowdfunding (financiamento coletivo) para escutar os "refugiados de Belo Monte", ou seja, as pessoas que foram desalojadas de suas casas e instaladas na periferia de Altamira, em condições precárias de existência, ocorrida sobre a implantação da Hidrelétrica de Belo Monte, no rio Xingu, Pará. Segundo Katz (2019) a violência do impacto excedeu a capacidade de elaboração simbólica da experiência pelo sujeito, assumindo um estatuto de trauma para essa população.

O projeto, construído pela jornalista Eliane Brum, Christian Dunker e llana Katz, estes últimos psicanalistas da USP- Universidade de São Paulo ganhou o nome singular de "Clínica de Cuidado".

Metodologicamente orientado pela psicanálise, a partir da violência que se fez presente no território, buscou atuar de forma que os atingidos pudessem realizar uma elaboração simbólica possível de alcançar. Os resultados até o momento obtidos permitiram aos autores entenderem, que na maior parte dos casos atendidos, houve uma mudança de posição do lado do sujeito ${ }^{26}$, como podemos ver nas palavras da D. Rosa,

\footnotetext{
24 "Futuro roubado": banalização da injustiça e do sofrimento social e ambiental na construção de hidrelétricas ". Tese de doutoramento de Carmen Giongo (2017). Disponibilização parcial do texto em https: //lume.ufrgs.br/handle/10183/158197.

${ }^{25}$ Fonte: https: //bdpi.usp.br/item/002898629/https: //www.latesfip.com.br/copia-capitulo-1-apsicanalise-nos-.

${ }^{26} \mathrm{http:} / /$ redehumanizasus.net/96635-o-que-pode-a-clinica-eliane-brun-nos-mostra-de-formabelissima/

http: //www.ihu.unisinos.br/78-noticias/584530-um-caminho-sem-retorno-o-trauma-de-belo-monte.
} 
(...) "sabe dona Maria, essa nossa conversa foi muito importante pra iluminar os pensamento... a gente fica aqui trancado e não vê...quando eu morava na ilha era tudo aberto, aquele rio que não acabava na vista, aqui não, essas grade é ruim pra gente. Eu gostei muito dessas prosa da vida da gente, nem precisa explica o que estão fazendo aqui não, eu já é entendi tudo - Eu sei o que vocês estão fazendo aqui...os filhos de Altamira estão esquecidos, vocês estão fazendo é memória" (Katz, 2019: 34).

O caso da Clínica da Escuta se impõe pelo seu próprio nome: escuta. A resistência, a construção de algo novo será sempre pela via da palavra e não pela imposição de um saber. Esse caminho, portanto, que se utiliza da orientação psicanalítica e seus dispositivos clínicos de escuta, entendemos que é que de grande valia no percurso da construção de uma Educação Ambiental crítica.

\section{CONSIDERAÇÕES FINAIS}

Iniciamos este artigo a partir da expressão de Agamben, que nos maravilha sobre as inúmeras possibilidades acerca de ser contemporâneo, algo que, na junção com o quadro atual socioambiental nas regiões litorâneas, impele-nos a essa aventura de pensar outras experiências em Educação Ambiental.

Procuramos demonstrar que a (de)-vasta-ação não é somente física, mas psíquica e, portanto, ética, situando uma desigualdade social sem precedentes, que rasga o tecido social em diferentes locais, sob diferentes contornos.

Reforçamos, a partir dos aspectos apresentados neste artigo, o que Dunker diz sobre ser "um erro supor, que em acordo com aquele velho antropomorfismo sociológico se escuta que o 'social sofre', 'uma comunidade sofre', 'uma família sofre'. O que se pretende dizer com tais afirmações? (Dunker, 2015:37)." Tal questionamento do autor nos leva a supor que entender os afetos - aquilo que nos afeta - de maneira homogênea, sem tomá-los em sua singularidade, significa atribuílos a alguém (algo) que não existe. O que de fato acontece é que os afetos dos indivíduos, por mais subjetivos ou concretos que sejam, são mediados por instâncias simbólicas, que vão desde a palavra até a ideologia. Logo, quando dizemos que uma comunidade sofre, a bem da verdade, devemos, além de posicionar a racionalidade econômica que os oprime, contar a história desses sujeitos e seu conjunto de pressupostos para poder dizer do que realmente se trata.

Para além, portanto, do sofrimento inerente à dor de existir, aqueles que estão em condições de grande vulnerabilidade socioambiental são alvo de uma 
violência de natureza psíquica, pelas diferentes nuances do poder, na forma de vida capitalista a qual estão expostos, como procuramos evidenciar através do pensamento de Safatle.

Freud já havia nos dito que não há separação entre indivíduo e coletivo, apesar dos afetos serem individuais não se pode abstrair das relações com os outros indivíduos (Freud, 1921/2011: 14). Por esta via, embora a situação de injustiça ambiental se ajuste atingindo de maneira mais direta e intensa aqueles que estão mais frágeis na organização social e sem recursos para minorar os efeitos desta, não há como negar que isto acabará afetando a todos.

Mas, por outro lado, no entanto, por mais incrível que nos pareça, lidar com esse cenário nos faz vislumbrar um contraponto importante, situando-nos adiante de uma interpretação de desesperança melancólica, como podemos ver na Clínica da Escuta.

Mais uma vez é com o filósofo Safatle (2017) a quem recorremos acerca em sua interpretação sobre o pensamento de Adorno, acerca das "fases em que o espírito do mundo, a totalidade, se obscurece e mesmo as pessoas notoriamente dotadas não conseguem se tornar o que são (Adorno, 2009: 195)". Segundo a interpretação de Safatle (op.cit), diante da obscuridade, cabe a cada um de nós escolher em qual situação pretende se colocar seja numa época de restrição de horizontes, em que as expectativas farão com que fiquemos menores do que seríamos ou em uma época de "horizontes incertos", não porque sejam inseguros, diz Safatle, mas exatamente pela sua mobilidade que nos permite ir para qualquer lugar, impulsionados para frente.

Nesse sentido somos otimistas ao entender que outras formas de vida são possíveis no tocante as nossas relações com a natureza; diferentes dessas que nos tornam seres privados, tanto da presença dos outros como aquelas que procedem da experiência de compartilhar um estado de mundo. Se os horizontes da nossa época apontam a incerteza e a obscuridade, por outro substanciam, num sentido mais amplo, a importância da Educação Ambiental no processo de disrupção da ordem hegemônica vigente.

Vemos a Educação Ambiental como da ordem de alguma coisa andante, que se põe (nos põe) em marcha, e nisso que cabe a ela pensar, justamente, sobre práticas educativas que enlacem os sujeitos na conservação e preservação do meio 
ambiente, como algo que a eles também pertence, entendemos necessário que tenhamos como horizonte incluir a compreensão da nossa subjetividade contemporânea nas faces que aqui procuramos mostrar.

Não há dúvidas que vivemos tempos de obscuridade, tempos onde não nos pautamos pela manutenção da vida, onde a dimensão do sofrimento humano atinge uma escala sem precedentes. Mas há que se reconhecer o legado político de Freud, que nos direciona a uma saída a partir do desamparo que sentimos nesse encontro com a obscuridade, de certa maneira, traumático. Safatle (2016) afirma que é do afeto de desamparo que surge a nossa emancipação e cabe a nós fazer coisas bastante diferentes, tais como transformá-lo em medo, em angústia social ou a partir dele, produzir um gesto forte potencial liberador.

Este é um trabalho que Freud nos ensinou, ancorado fundamentalmente na escuta singular dos sujeitos, mas que se abre, no sentido de uma psicanálise ampliada, "possibilitando esta escuta sob diversas maneiras, desde oficinas, nas instituições, na articulação de redes de assistência, na divulgação dos acontecimentos e conflitos (Rosa, 2016: 195)".

$\mathrm{Na}$ complexidade das questões socioambientais nos parece fazer sentido, então, que a Educação Ambiental, enquanto intervenção coletiva em esferas públicas, também partilhe da responsabilidade na reorganização do campo simbólico, incluindo a ressignificação dos restos deixados pelos eventos traumáticos, de cunho socioambiental, num correlato à "cura social" termo proposto por Gagnebin (2006: 59 apud Kehl, 2009: 27).

A Educação Ambiental deve estar aberta a discutir sobre as incidências do Outro social sobre a subjetividade, abrindo-se à falta de saber, recusando apenas o saber teórico formal, colocando-se aos desafios socioambientais do nosso tempo, não recuando diante de todo o mal-estar.

Leff (2011) já havia nos dito que a relação entre o "saber ambiental e a psicanálise" desconstroem as certezas da modernidade, abrindo novos horizontes de possibilidades à vida e à história (Leff, 2011: 195) e, por isso, talvez não haja plano a ser seguido, nem ações mirabolantes, mas sim construir pontes para dar ao sujeito excluído um lugar em que possa colocar em palavras, os seus afetos, a sua história e, nisto, que se torna um laço também permite um giro ao ato, ou seja, algo aí que lhe permitirá se posicionar de outra maneira. $E$ isto é muito. 


\section{AGRADECIMENTOS}

Agradecemos o apoio da FUNDAÇÃO ARAUCÁRIA - CAPES para a elaboração deste trabalho.

\section{REFERÊNCIAS}

ADORNO, Theodor. Dialética negativa. Rio de Janeiro: Jorge Zahar. 2009.

AGAMBEN, Giorgio. Homo Sacer: o poder soberano e a vida nua. Trad. Henrique Burigo, Belo Horizonte: Editora UFMG, 2002.

O que é o contemporâneo? e outros ensaios. Tradução de Vinicius Nicastro Honesko. Chapecó. Argus, 2009. p. 55-76.

ANDRIGUETTO FILHO, José Milton. Das "dinâmicas naturais" aos "usos e conflitos": uma reflexão sobre a evolução epistemológica da linha do "costeiro".

Desenvolvimento e Meio Ambiente, v. 10, p. 187-192, 2004.

AZEVEDO, Natália Tavares. A vulnerabilidade social dos municípios do litoral do Paraná: construção do Índice de Vulnerabilidade Social (IVS) com base nos dados dos setores censitários IBGE 2010. Revista Guaju, v. 2, 2016.

BIRMAN, Joel. A economia do gozo e os impasses da justiça. Uma leitura psicanalítica da justiça. Physis [online], vol.6, n.1-2, pp.121-134, 1996. http: //dx.doi.org/10.1590/S0103-73311996000100006. Acesso em 15 outubro de 2017.

CHEMAMA, Roland. (Org.) Dicionário de Psicanálise. Porto Alegre: LarousseArtes Médicas Sul. 1995.

CHEREM, Maria Fernanda; AZEVEDO, Natália. Conflitos socioambientais e processos de resistência de pescadores artesanais no litoral do Paraná. In: 40 Encontro Anual da ANPOCS, 2016, Caxambu. Anais do 40 Encontro Anual da ANPOCS, 2016.

CEZAR JUNIOR, Gervásio. Organização do projeto neoliberal no anos 1970: Revista Visão e sua ação orgânica partidária. In: VI Simpósio Nacional Estado e Poder: Cultura, 2010. Disponível em http: //www.eeh2010.anpuhrs.org.br/resources/anais/9/1279397247 ARQUIVO TextoparaAnais.pdf

DUNKER, Christian Ingo Lenz. Mal-estar, sofrimento e sintoma: releitura da diagnóstica lacaniana a partir do perspectivismo animista. Tempo Social, São Paulo, v. 23, n. 1, p. 115-136, jan. 2011. Disponível em http: //www.revistas.usp.br/ts/article/view/12654. Acesso em 28 de agosto de 2019.

Mal-estar, sofrimento e sintoma: uma psicopatologia do Brasil entre muros. 1르ed.São Paulo: Boitempo. 2015 
Clínica e diagnóstico na era neoliberal. 2016. Disponível em https: //www.youtube.com/watch?time continue $=860 \& \mathrm{v}=3$ noUnc0emC8 Acesso em 28 de agosto de 2019.

DUNKER, Christian Ingo Lenz; FRAGELLI, Ilana Katz Zagury. A clínica do cuidado: intervenção com a população ribeirinha do Xingu atingida por Belo Monte. Anais.. São Paulo: Instituto de Psicologia. Universidade de São Paulo, 2018.

FARACO, Luís; ANDRIGUETTO FILHO, José Milton; DAW; Tim; LANA, Paulo da Cunha; TEIXEIRA, Cristina. Vulnerability Among Fishers in Southern Brazil and its Relation to Marine Protected Areas in a Scenario of Declining Fisheries.

Desenvolvimento e Meio Ambiente, v. 38, p. 51-76, 2016.

FARIAS, Ana Lizete. A emergência do saber ambiental numa perspectiva psicanalítica. In: EPEA 2017- Encontro Paranaense de Educação Ambiental, 2017, CURITIBA. Anais do XVI Encontro Paranaense de Educação Ambiental, 2017.

FARIAS, Ana Lizete; KNECHTEL, Maria do Rosário. Uma perspectiva psicanalítica para a Educação Ambiental. Ambiente \& Educação: Revista de Educação Ambiental, v. 23, p. 322-338, 2018.

FREUD, Sigmund. A pulsão e seus destinos. 1914-1915. Obras incompletas de Sigmund Freud. Tradução de Pedro Heliodoro Tavares. Belo Horizonte.Ed.Autentica. 2013.

Luto e Melancolia. (1915-1917). Tradução de Marilene Carone. São Paulo: Cosac Naify, 2011.

Psicologia das Massas e Análise do Eu e outros textos .1920-1923.; tradução de Paulo Cesar de Souza. São Paulo: Companhia das Letras 2011.

O mal-estar na civilização, novas conferencias introdutórias à psicanálise e outros textos .1930-1936. Tradução de Paulo Cesar de Souza. São Paulo: Companhia das Letras, 2010.

GAGNEBIN, Jeanne Marie. Memória, história, testemunho. In J. M. Gagnebin, Lembrar, escrever, esquecer (pp. 49-57). São Paulo: Editora 34, 2006.

GIONGO, Carmen Regina . Futuro roubado: banalização da injustiça e do sofrimento social e ambiental na construção de hidrelétricas. Tese de doutorado .Universidade Federal do Rio Grande do Sul, Programa de Pós- Graduação em Psicologia Social e Institucional, Porto Alegre, 2017.

KATZ, Ilana. Psicanálise nos espaços públicos. Emília Broide e llana (org.). São Paulo : IP/USP, 2019.

KEHL, Maria Rita. O tempo e o cão: a atualidade das depressões. São Paulo: Boitempo, 2009.

Melancolia e criação. Resenha de Freud, Sigmund Carone, Modesto e Carone, Marilene (tradução de Marilene Carone). São Paulo: Cosac Naify, 2011. 
LACAN, Jacques. Função e campo da fala e da linguagem em psicanálise. In J. Lacan, Escritos (pp. 238-324). Rio de Janeiro: Jorge Zahar, 1998. (Trabalho original publicado em 1953).

LAYRARGUES, Philippe Pomier; LIMA, Gustavo Ferreira da Costa. "As macrotendências político-pedagógicas da educação ambiental brasileira". Revista Ambiente e Sociedade. São Paulo, v. XVII, no 1, p. 23-40, jan-mar/2014.

LEFF,Enrique. Saber ambiental: sustentabilidade, racionalidade, complexidade, poder. Petropolis, RJ: Ed. Vozes, 2011.

LOSEKANN, Cristiana. "Não foi acidente!" o lugar das emoções na mobilização dos afetados pela ruptura da barragem de rejeitos da mineradora Samarco no Brasil. In: Zhouri, Andréa (Org); R. Oliveira et al. Mineração: violências e resistências: um campo aberto à produção de conhecimento no Brasil. Marabá-PA: Iguana, 2018.Disponível em : http: //www.scielo.br/scielo.php?pid=S180943412017000200303\&script=sci abstract\&tlng=pt Acesso em 10 de setembro de 2019.

MORAES, Maria Esmeralda. A ocupação antrópica e as questões ambientais no ecossistema restinga - O caso do perímetro urbano do município de Paranaguá. In: Meio Ambiente e Desenvolvimento do Litoral do Paraná: Diagnóstico Curitiba: Editora UFPR - NIMAD/CNPq, 1998. P 145-153.

MORAES, Antônio Carlos Robert. Bases da formação territorial do Brasil. O território colonial brasileiro no "longo" século XVI. São Paulo: Hucitec, 2000. 431 p.

MULLER, Marcelo. Análise das variações da linha de costa nas margens do mar do Ararapira como subsídio ao planejamento do uso e ocupação. Monografia apresentada ao curso de Graduação em Oceanografia, Setor de Ciências da Terra da Universidade Federal do Paraná, como requisito parcial à obtenção do título de Bacharel em Oceanografia. Universidade Federal do Paraná, 2007.

NASCIMENTO, Evandro; SILVA, Hugo Juliano Hermógenes da; SILVA, Maria Fernanda C.C. Bezerra; DENKEWICZ, Patrícia; VIEIRA, Raquel dos Santos.; CORBARI, Sandra Dalila. Diagnóstico e problematização do litoral do paraná vetores de produção socioespacial - porto e indústria, turismo e políticas e ações de conservação e gestão ambiental - e conflitos, resistências e alternatividades. Trabalho coletivo Linha de Pesquisa Usos e Conflitos em Ambientes Costeiros. Curitiba: PPGMade/UFPR, 2017.

NASIO, Juan-Davi. O livro da dor e do amor. Rio de Janeiro: Jorge Zahar Ed. 1997.

PIERRI, Naína; ANGULO, Rodolfo Jose; SOUZA, Maria Cristina de; KIM, Minela. A ocupação e o uso do solo no litoral paranaense: condicionantes, conflitos e tendências. Desenvolvimento e Meio Ambiente, v.13, p. 137-167, 2006.

RAINHO, Ana Paula. 2015. A gente vive no mar: saberes oceanográficos na comunidade tradicional Barra da Ararapira. Dissertação (mestrado em Antropologia Social). Universidade Federal do Paraná, 171 p. 
ROSA, Miriam Debieux. A clínica psicanalítica em face da dimensão sociopolítica do sofrimento. São Paulo: Escuta/Fapesp, 2016.

ROUDINESCO, Elisabeth. Por que a psicanálise? Rio de Janeiro: Jorge Zahar. 2000.

TOLEDO, Adilson do Rosário. ; GASPARINI, Bruno . Conflitos socioambientais nas áreas de proteção ambiental do litoral do Paraná. Revista Direito à Sustentabilidade, v. V. 2, p. 9-31, 2015.

SAFATLE, Vladimir. O circuito dos afetos: corpos políticos, desamparo e o fim do indivíduo. Belo Horizonte: Autêntica, 2016.

Melancolia do poder .Café Filosófico, 2017. Disponível em https: //www.youtube.com/watch?v=LLLxyYgWzQA Acesso em 20 de setembro de 2019.

Dar corpo ao impossível: o sentido da dialética a partir de Theodor Adorno. Belo Horizonte. Autentica, Editora. 2019.

ZHOURI, Andréa; VALENCIO ,Norma; OLIVEIRA ,Raquel; ZUCARELLI, Marcos; LASCHEFSK, Klemens; SANTOS, Ana Flávia. O desastre da Samarco e a política das afetações: classificações e ações que produzem o sofrimento social. Cienc. Cult., São Paulo, v. 68, n. 3, p. 36-40, Sept. 2016 . Available from <http: //cienciaecultura.bvs.br/scielo.php?script=sci_arttext\&pid=S000967252016000300012\&lng=en\&nrm=iso > . access on 22 Oct. 2017. http: //dx.doi.org/10.21800/2317-66602016000300012.Acesso em: 20 de agosto de 2019. 